\title{
The feasibility of wireless capsule endoscopy in detecting small intestinal pathology in children under the age of 8 years: a multicentre European study
}

\author{
A Fritscher-Ravens, ${ }^{1}$ P Scherbakov, ${ }^{2}$ P Bufler, ${ }^{3}$ F Torroni, ${ }^{4}$ T Ruuska, ${ }^{5}$ H Nuutinen, ${ }^{6}$ \\ M Thomson, ${ }^{7} \mathrm{M}$ Tabbers, ${ }^{8} \mathrm{P}$ Milla ${ }^{9}$
}

${ }^{1}$ Homerton University Hospital, London, UK; ${ }^{2}$ Academy of Medical Sciences, Moscow, Russia; ${ }^{3}$ Children's Hospital, Munich, Germany; ${ }^{4}$ Bambino Gesu Hospital, Rome, Italy:

${ }^{5}$ University Hospital, Tampere, Finland: ${ }^{6}$ Children's Hospital, Helsinki, Finland; ${ }^{7}$ Children's Hospital, Sheffield, UK; ${ }^{8}$ Emma Children's Hospital, AMC Amsterdam, Netherlands; ${ }^{9} \mathrm{UCL}$ Institute of Child Health London, UK

Correspondence to:

Professor A Fritscher-Ravens, Department of Gastroenterology, Homerton University Hospital, Homerton Row, London E9 6SR, UK: fri.rav@btopenworld.com

Revised 9 April 2009 Accepted 14 April 2009 Published Online First 21 July 2009

\section{ABSTRACT}

Objective: To systematically evaluate the feasibility and methodology to carry out wireless capsule endoscopy (WCE) in children $<8$ years to define small intestinal pathology.

Design: Prospective European multicentre study with negative prior investigation.

Patients and interventions: 83 children aged 1.57.9 years were recruited. Initially, all were offered "swallowing" (Group 1) for capsule introduction. If this failed endoscopic placement (Group 2) was used and the Roth net, Advance or custom-made introducers were compared.

Outcome measures: Primary endpoint: to determine pathology; secondary endpoint: comparison of capsule introduction methods.

Results: Capsule introduction: 20 (24\%) children aged 4.0-7.9 years (mean, 6.9 years; 14 male) comprising Group 1 were older $(p<0.025)$ than $63(76 \%)$ aged $1.5-$ 7.9 years (mean, 5.25 years; 30 male) forming Group 2. Complications: Roth net mucosal trauma in 50\%; no others occurred. The available recording apparatus was inappropriate for those $<3$ years. Indications: gastrointestinal bleeding: $n=30$ (16 positive findings: four ulcerative jejunitis, four polyps, two angiodysplasia, two blue rubber blebs, two Meckel's diverticula, one anastomotic ulcer, one reduplication); suspected Crohn's disease: $n=20$ (11 had Crohn's disease); abdominal pain: $n=12$ (six positive findings: three Crohn's disease, two lymphonodular hyperplasia, one blue rubber bleb); protein loss: $n=9$ (four lymphangectasia); malabsorption: $\mathrm{n}=12$ (seven positive findings: six enteropathy, one ascaris). No abnormalities overall: $45 \%$.

Conclusion: WCE is feasible and safe down to the age of 1.5 years. 20 children $>4$ years swallowed the capsule. The Advance introducer proved superior for endoscopic placement. The pathologies encountered showed age specificity and, unlike in adolescents, obscure gastrointestinal bleeding was the commonest indication.

Investigations in small children always require special consideration compared to adults, as paediatric patients have limited understanding of procedures, and a great fear of a foreign environment. In addition, some agents, such as $x$ rays, are potentially damaging, and devices and instruments are often not suitable. This is particularly evident when the small bowel requires examination. As in adults, radiological tests are mostly insensitive and double balloon enteroscopy is unsuitable for the younger child. ${ }^{1-4}$
As a consequence understanding of mucosal pathology and the ability to diagnose lesions of the jejunum and upper ileum is limited. There is thus a clinical need for improved methods of examining the small bowel in the young child.

The introduction of wireless capsule endoscopy (WCE) has made available a new, powerful, noninvasive imaging modality. Since the United States Food and Drug Administration (FDA) approved the use of WCE in patients >10 years in 2001 the technique has been shown to be a safe with no pain and few complications. ${ }^{5-14}$ The knowledge obtained since its introduction has provided new insights into a variety of diseases ${ }^{15-32}$ and has altered the management of patients with small intestinal diseases previously investigated with little success by a variety of endoscopic and radiological techniques. ${ }^{3} 91415$

Several case reports, some studies and reviews of WCE in older children and adolescents have now been published, in whom it has been shown to be a safe and effective means of detecting small intestinal pathology. They are also able to swallow the capsule and carry the necessary equipment. Systematic studies of children $<8$ years are not available but anecdotal evidence in case reports and papers reporting 19 children show WCE to be feasible in this age group..$^{22-26}$

There is, however, a need for robust and systematically obtained data of WCE in young children, as to date the indications are unclear, the most suitable method of introduction into the small bowel, if the capsule cannot be swallowed, not analysed and possible complications unknown. In this paper we describe a European multicentre study of children under the age of 8 years, systematically enrolled for WCE of the small bowel when routine endoscopy and radiological tests failed to define pathology which explained their symptoms. A secondary goal was to compare different means of introducing the capsule into the bowel in those children who could not swallow it.

\section{PATIENTS AND METHODS \\ Patients}

Eighty-three children aged $1.5-7.9$ years (37 male, 45 female) were recruited by nine paediatric centres throughout Europe. Their age distribution is shown in table 1.

Children with occult gastrointestinal bleeding, suspected Crohn's disease, abdominal pain of unknown aetiology, protein-losing enteropathy and malabsorptive disorders were enrolled into 
Table 1 Age distribution of the patients

\begin{tabular}{ll}
\hline Age (years) & Number of patients \\
\hline$<3$ & $6^{*}$ \\
$3-4$ & 14 \\
$4-5$ & 15 \\
$5-6$ & 14 \\
$6-7$ & 16 \\
$7-8$ & 18 \\
\hline
\end{tabular}

${ }^{*}$ The ages of six patients who were $<3$ years were $1.5,1.7,1.8$, $2.1,2.5$ and 2.7 years.

the study if a standard barium meal and follow-through to the terminal ileum, or abdominal magnetic resonance imaging and upper gastrointestinal (GI) endoscopy and colonoscopy to the caecum with biopsies carried out prior to the study were negative or excluded small intestinal obstruction.

Exclusion criteria were children with oesophageal stricture, small bowel and colonic stenosis or untreated congenital bleeding disorders or under 1 year of age.

\section{Methods}

A standard Pillcam $(11 \times 26 \mathrm{~mm}, 3.3 \mathrm{~g}$; Given Imaging, Yoqneam, Israel) capsule was used with paediatric- and adultsized aerial sensor arrays, wireless receiver, data recorder and battery with a video imaging capture time of $\sim 8 \mathrm{~h}$ producing $\sim 50000$ images. The light was produced by white-light emitting diodes and the images by a complementary metal oxide silicon imager containing $256 \times 256$ pixels. The digital signal was stored on a portable recorder, which was carried on a belt around the patient's waist, in a custom-made rucksack as shown in fig 1 or, in the smallest children, placed beside them on their cots.

All patients were given clear fluids for $24 \mathrm{~h}$ before the study and fasted for $12 \mathrm{~h}$ overnight prior to the study. Further

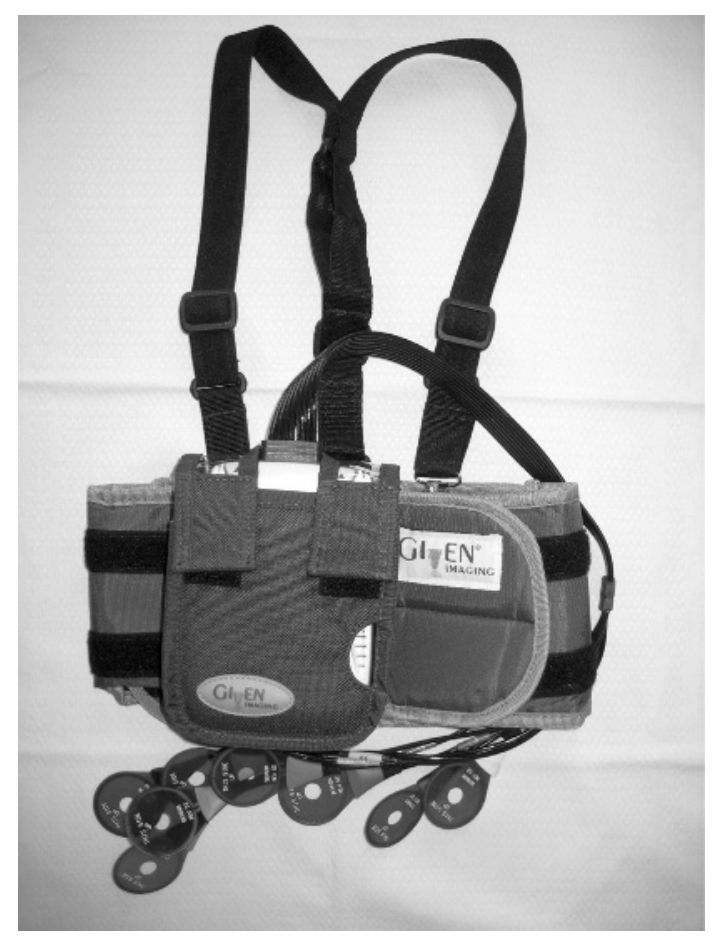

Figure 1 A custom-made rucksack for the batteries and recorder in small children. preparation was left to each participating centre and is summarised in table 2.

In order to compare endoscopic methods of capsule deployment and the devices required for this, the children were separated into two groups. Initially, all were offered "swallowing" for capsule introduction. Group 1 consisted of children who were willing (or could be persuaded) to swallow the capsule; while Group 2 consisted of patients who were unable to swallow the capsule, and required endoscopic placement of the capsule into the duodenum. Devices used included: (1) Roth net; ${ }^{33}$ (2) Advance introducer (US Endoscopy, Mentor, Ohio, USA); and (3) a custom-made acorn-like device. ${ }^{34}$ The choice of the insertion device was left to the endoscopist, but any complications directly attributable to the endoscopic introduction and the ease or difficulty in carrying it out were noted and the methods and devices were compared.

Two hours after introduction of the capsule the patients were allowed to drink clear fluids and after $4 \mathrm{~h}$ to have a light meal. Patients or their parents were asked to note when the capsule was passed in the child's stools and to recover the capsule. Any complications encountered were noted.

The video observers were asked to assess any macroscopic pathological lesions, the number of lesions, and to attempt to define their approximate position in the small bowel.

\section{Statistical analysis}

The patient demography and observations were entered into a Microsoft Excel spreadsheet by the different recruiting centres, collated and then subjected to statistical analysis. The Student t test and a $\chi^{2}$ test were used for normally distributed populations. Data are expressed as range and mean. All $p$ values $<0.05$ were considered statistically significant.

\section{Ethics}

A unified ethical proposal was provided for the study participants as a template for individual applications for approval by the appropriate ethics board of each centre. Approval for the study was obtained for each of the participating centres after additional requests from some centres' ethical review boards were complied with. Three ethical review boards feared that capsule retention would occur in such young children. One requested that preliminary $x$ ray studies should only be done if there was a suspicion of obstructive symptoms. A further board requested a small number of post-mortem investigations to prove that the capsule would traverse the ileocaecal valve in infants as young as 1 year of age. These preliminary additional studies using dummy capsules were carried out at the Ludwig-Maximilian University, Munich, Germany, showed that a normal-sized capsule could traverse the ileo-caecal valve in infants down to age 6 months and through the pylorus down to 1 year and $10 \mathrm{~kg}$ body weight. These results were in accordance with at least one previous report demonstrating that there was no correlation between body size and capsule retention. ${ }^{22}$

\section{RESULTS}

Eighty-five studies were carried out in the 83 children aged 1.57.9 years (44 male). Four (4.7\%) studies in three children were incomplete. In two children battery failure at 2.5 and $3.5 \mathrm{~h}$, respectively, was noted but, in both, relevant diagnostic information was obtained. In another child the capsule failed to exit the stomach on two different occasions. Subsequently, it was introduced into the duodenum endoscopically. 
Table 2 Bowel preparations used in the participating centres

\begin{tabular}{llll}
\hline Bowel preparation & Centres, $\mathbf{n}$ & Patients \% & Outcome \\
\hline Clear fluids only & 3 & 40 & Mucosa satisfactorily seen, but some food residues \\
+ Senna \& picolax & 1 & 8 & $\begin{array}{l}\text { 3 patients vomited during preparation. Mucosa partially obscured but } \\
\text { positive diagnoses made }\end{array}$ \\
+Klean Prep & 5 & 52 & Good preparation but bubbles in some. Mucosa well seen \\
\hline
\end{tabular}

Twenty (24\%) children aged $4.0-7.9$ years (mean, 6.9 years; 14 male) were able to swallow the capsule (Group 1), while 63 $(76 \%)$ aged $1.5-7.9$ years (mean, 5.25 years; 30 male) were unable to swallow it (Group 2), as shown in table 3.

The children in Group 1 were significantly older than those in Group 2 (Group 1, 4.0-7.9 years, mean 6.9 years; Group 2, 1.57.9 years, mean 5.25 years; $p<0.025$ ). The youngest child to swallow the capsule was a boy of 4 years of age. More than twice the number of boys $(n=14)$ were willing to swallow the capsule compared to girls $(n=6)$. In Group 2 it was possible to introduce the capsule endoscopically into the duodenum in all infants $(n=63)$ from 1.5 years of age and $10 \mathrm{~kg}$ weight. Unlike patients in Group 1 there was no difference in sex distribution (30 male) in Group 2.

\section{Introduction of the endoscopic capsule}

Of the 63 children in whom the capsule was introduced endoscopically, the Advance introducer was used in 39, a custom-made introducer ${ }^{34}$ in 16 and the Roth net ${ }^{33}$ in eight.

After the first 20 patients had been studied ( $n=12$, Advance introducer; $\mathrm{n}=8$, Roth net) significant mucosal trauma was noted in $50 \%$ of procedures carried out with the Roth net. The rigid tip of the wire holding the net led to injuries of the mucosa when intubating the oesophagus and again but less severe on pushing the net through the pylorus. In addition it proved cumbersome to empty the capsule from the net in the rather confined space of the duodenum. With the Advance introducer capsule introduction proceeded uneventfully and it proved easier to handle. The Roth net was subsequently abandoned and the Advance introducer used in all centres except one, in which the custom-made device was used throughout.

\section{Adverse events}

Significant mucosal trauma occurred in the pharynx $(n=2)$ at the upper oesophageal sphincter $(n=3)$ and the pylorus $(n=1)$ in $4 / 8$ patients in whom the Roth net was used. No further complication was noted and specifically no capsule retention occurred.

\section{Clinical indications}

WCE was undertaken for occult GI bleeding $(\mathrm{n}=30)$, suspected Crohn's disease $(n=20)$, abdominal pain of unknown aetiology $(n=12)$, protein-losing enteropathy $(n=9)$ and malabsorption $(\mathrm{n}=12)$ in children in whom standard investigations had failed to yield the cause of their symptoms. Patients with obscure GI bleeding, protein-losing enteropathy and malabsorption were significantly younger than those suspected of having Crohn's disease or recurrent abdominal pain, as shown in table 4.

Crohn's disease (8/20) was the commonest indication in Group 1, followed by GI bleeding (6/20), whereas in Group 2, the majority of patients were investigated for occult GI bleeding $(24 / 63)$. The remainder of the patients in both groups were fairly evenly distributed between the remaining three indications (table 3 ).

\section{Obscure gastrointestinal bleeding}

WCE identified a source of bleeding in 16/30 (age 1.5-7 years, mean 4.5 years) patients with obscure GI bleeding and/or chronic anaemia, six of whom were blood transfusion dependent. These included four children with an ulcerative jejunitis, three of whom were non-steroidal anti-inflammatory drug related. All of these children suffered from juvenile rheumatoid arthritis. Four children had polyps, two with Peutz-Jegher's syndrome and two nonsyndromic juvenile polyposis (fig 2A), two angiodysplasia (fig 2B), two "blue rubber bleb"-type haemangiomas, two Meckel's diverticulae, one astomotic ulcer (fig 2C) and one reduplication of the intestine. In 14/30 children the source of bleeding could not be found by WCE. In two patients, lesions which were not bleeding were found: one lymphonodular hyperplasia and one patchy partial villous atrophy. In 12 patients, no lesions were found by WCE, two of whom were non-symptomatic at the time of the study.

\section{Suspected Crohn's disease}

Twenty children (age 5-8 years, mean 7.35 years) were suspected of suffering from small intestinal Crohn's disease but in whom upper and lower intestinal endoscopy failed to provide a diagnosis. In 11/20 evidence of small intestinal Crohn's disease was found which varied from diffuse apthous ulcerations (fig 2D) throughout the small bowel to deeper ulceration and fissuring with (fig 2E) terminal ileitis. All 11 of the patients had evidence of acute active disease. In three, additional colonic disease was found with WCE although the screening colonoscopy had been negative. In 9/20 children no lesions were found.

Table 3 Method of introducing the capsule into the duodenum of children in Groups 1 and 2

\begin{tabular}{|c|c|c|c|c|c|c|c|}
\hline \multirow[b]{2}{*}{ Group } & \multicolumn{2}{|c|}{ Age (years) } & \multicolumn{2}{|l|}{ Sex } & \multirow[b]{2}{*}{ Method } & \multirow[b]{2}{*}{$\mathbf{n}$} & \multirow[b]{2}{*}{ Compl" $^{\mathrm{n}}$} \\
\hline & Range & Mean & Male & Female & & & \\
\hline 1 & $4.0-7.9$ & 6.9 & 14 & 6 & Swallow & 20 & 0 \\
\hline \multirow[t]{3}{*}{2} & $1.5-7.5$ & 5.25 & 30 & 33 & Roth net & 8 & 4 \\
\hline & & & & & Advance & 39 & 0 \\
\hline & & & & & Custom made & 16 & 0 \\
\hline Total & $1.5-7.9$ & 5.11 & 44 & 39 & & 83 & 4 \\
\hline
\end{tabular}

Difference in age range group 1 vs group $2: p \leqslant 0.05$.

Compl ${ }^{\text {n: }}$ complications. 
Table 4 Indications and findings of positive capsule studies and their distribution among the groups overall

\begin{tabular}{|c|c|c|c|c|c|c|}
\hline & $\begin{array}{l}\text { Age range, } \\
\text { years (mean) }\end{array}$ & Patients, n & $\begin{array}{l}\text { Positive } \\
\text { studies, n }\end{array}$ & Findings & $\mathbf{n}$ & $\begin{array}{l}\text { No } \\
\text { pathology, n }\end{array}$ \\
\hline \multirow{7}{*}{$\begin{array}{l}\text { Gastrointestinal } \\
\text { bleeding }\end{array}$} & $1.5-7.0(4.5)$ & 30 & 16 & Ulcerative jejunitis & 4 & 14 \\
\hline & & & & Polyposis & 4 & \\
\hline & & & & Angiodysplasia & 2 & \\
\hline & & & & Blue rubber bleb & 2 & \\
\hline & & & & Meckel's diverticulum & 2 & \\
\hline & & & & Anastomotic ulcer & 1 & \\
\hline & & & & Reduplication & 1 & \\
\hline \multirow[t]{2}{*}{ Crohn's disease } & $5.0-7.9(7.35)$ & 20 & 11 & Small intestinal Crohn's disease & 8 & 9 \\
\hline & & & & Crohn's colitis & 3 & \\
\hline \multirow[t]{3}{*}{ Abdominal pain } & $4.5-7.9(6.3)$ & 12 & 6 & Small intestinal Crohn's disease & 3 & 6 \\
\hline & & & & Lymphonodular hyperplasia & 2 & \\
\hline & & & & Blue rubber bleb & 1 & \\
\hline \multirow[t]{2}{*}{ Protein loss } & $1.5-7.5(4.1)$ & 9 & 6 & Lymphangectasia & 4 & 3 \\
\hline & & & & Lymphonodular hyperplasia & 2 & \\
\hline \multirow[t]{3}{*}{ Malabsorption } & $3.0-7.5(4.8)$ & 12 & 6 & Non-coeliac & & 6 \\
\hline & & & & Enteropathy & 6 & \\
\hline & & & & Ascaris & 1 & \\
\hline
\end{tabular}

Difference in age range: gastrointestinal bleeding vs Crohn's disease, $p \leqslant 0.01$; gastrointestinal bleeding vs abdominal pain, $p \leqslant 0.05$; protein-losing enteropathy vs Crohn's disease, $p \leqslant 0.01$; protein-losing enteropathy vs abdominal pain, $p \leqslant 0.05$; malabsorption vs Crohn's disease, $\mathrm{p} \leqslant 0.01$; and malabsorption vs abdominal pain, $\mathrm{p} \leqslant 0.05$.

\section{Abdominal pain}

Six of 12 patients (age 4.5-8.0 years, mean 6.3 years) with recurrent abdominal pain were found to have significant pathology. Three patients had small intestinal Crohn's disease (fig 2D,E), which accounted for the complaints, one had a "blue rubber bleb", and two had lymphonodular hyperplasia, one of whom had juvenile rheumatoid arthritis. The other six children had completely normal studies. In two of those a final diagnosis of non-ulcer dyspepsia was made on further investigation. ${ }^{35}$

\section{Protein-losing enteropathy}

Nine children (2.5-7.5 years, mean 4.1 years) had protein loss from the bowel for which no cause had been found. Despite normal duodenal biopsies, four had lymphangectasia and two had lymphonodular hyperplasia on WCE. The remaining three children had no detectable abnormality of their small intestine.

\section{Malabsorption}

Of the 12 patients (3.0-7.5 years, mean 4.8 years) with malabsorption and suspected enteropathy in six, all of whom had normal duodenal histology at prior endoscopy, varying degrees of villous atrophy were detected on WCE. Two of those had subtotal and four patchy partial villous atrophy. In none of the six patients was the final diagnosis coeliac disease. In the remaining six children no abnormality of the small intestine was detected. One had sucrose intolerance and two were food allergic but in three no cause was found for their failure to thrive at the time of this study, although in one patient there was an infestation with Ascaris lumbricoides (fig 2F).

\section{Technical considerations}

In the older toddlers ( $>3$ years) and children up to 8 years of age there was enough room on the abdomen for the aerial electrodes and although the battery pack and recorder were heavy for the children they were able to carry them using the normal harness. For the youngest children the aerial sensors were trimmed to allow them to be placed on the abdomen in the appropriate position. The normal harness with battery pack and recorder was far too big and heavy for them. For these infants and toddlers the harness batteries and recorder were simply placed in the cot or "buggy" beside them or carried in a rucksack containing the battery pack and recorder (fig 1).

\section{DISCUSSION}

WCE is an endoscopic technique that offers an extremely safe approach to the investigation of small bowel pathology in adults and is potentially applicable in children where the alternatives are invasive, uncomfortable or require ionising radiation. ${ }^{26}$ To our knowledge only few capsule examinations in children of $<8$ years have been reported in the literature. ${ }^{22-26}$ The inability to swallow the capsule, a fear of capsule retention and a lack of FDA approval in this age group in the US, accompanied by the smaller number of patients requiring evaluation of the small bowel, have severely restricted systematic evaluation. The paucity of previous studies resulted in this multicentre approach in order to recruit sufficient children to systematically evaluate WCE in small children.

A major concern of both investigators and ethical review boards was the fear of capsule retention, which has been shown to be the most frequent complication of $1-2 \% .^{57}$ As a consequence preliminary post-mortem studies were performed in one centre, which successfully proved the ability of the capsule to traverse the pylorus and ileo-caecal valve in infants of 1 year of age. There were no instances of capsule retention in the 85 examinations of our group with the smallest child weighing just $10 \mathrm{~kg}$. This might occur, however, if a larger group of infants was examined even if care was taken to exclude obstructive conditions. But it seems that there is no higher incidence to be feared when compared to adults. ${ }^{57}$

Failure of the capsule to exit the stomach may be experienced in the presence of accompanying diseases including neurological or motility disorders, which was seen in our study. As a consequence it might be worthwhile to use endoscopic insertion as the first choice rather than swallowing in these children. If drugs such as opiates, which influence peristalsis, are used as well ${ }^{37}$ the effects may be similar. 
Figure 2 Small intestinal lesions causing obscure gastrointestinal bleeding. (a) Juvenile polyp, (b) angiodysplasia, and (c) anastomotic ulcer. (d) Apthous ulceration and (e) ulceration and fissures in small intestinal Crohn's disease.

(f) Malabsorption due to an Ascaris lumbricoides infestation. a

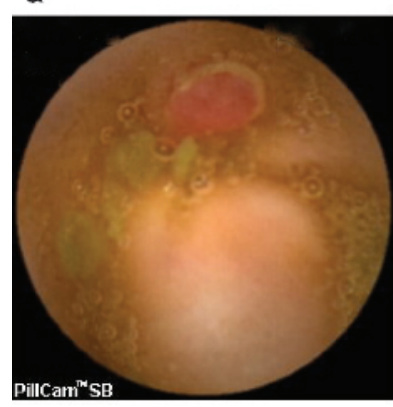

d

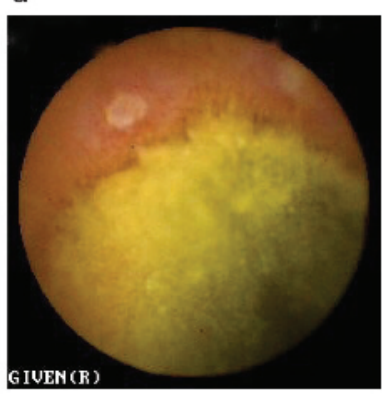

b

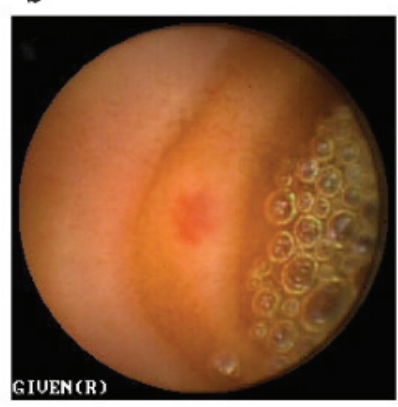

e

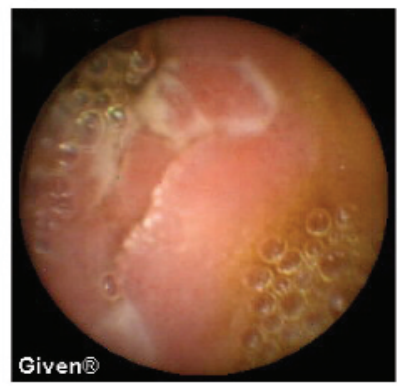

C

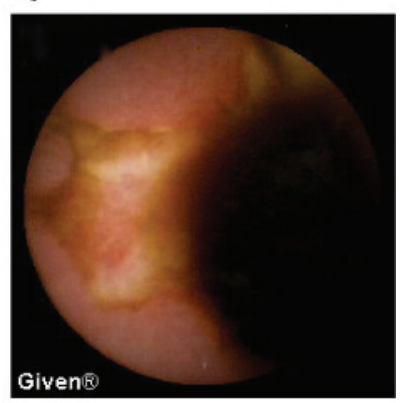

f

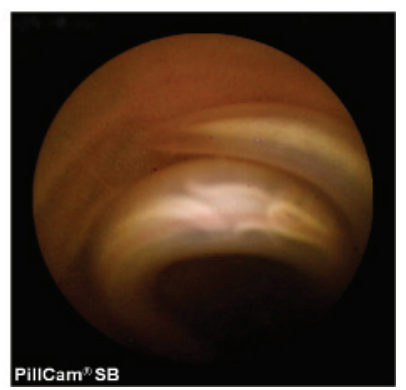

In a previous review it was stated that children under the age of 9 years $^{37}$ would be unable to swallow the capsule due to its large size. In this study $24 \%$ of the recruited children swallowed it without undue difficulty, the youngest being just 4 years of age. Various factors accounted for the fact that a child could or would swallow the device. These included the child's personality, acceptance by the parent(s) that the capsule could be swallowed and the skill of the investigator in challenging the child's ability. In this study boys were significantly more likely to swallow it than girls (14 boys vs 6 girls; $p=0.025$ ). The ability of the investigator to turn the investigation into an interactive game was a major factor, which proved more helpful than previous suggestions of training with candies. ${ }^{17}$

However, endoscopic introduction into the duodenum was necessary in the majority of children (76\%). The use of the Roth net resulted in mucosal trauma in $50 \%$ of the patients and was cumbersome to use even if an end-cap ${ }^{33}$ was added. It was thus abandoned, especially when the purpose-made Advance introducer proved to be easier to handle and non-traumatic. But the loaded capsule increases the overall diameter and it was previously thought to be unsuitable for use in infants. ${ }^{22}$ These concerns proved unjustified in our study.
To the best of our knowledge, there have been no studies of bowel preparation in young children and its necessity is controversial. ${ }^{11}{ }^{37}$ We left the mode of preparation to the single centres, as each of them reported good experience with "their" certain method. Although we did not carry out a formal study the results seen after using three different methods amongst the participating centres as described in table 2 show that clear fluids $24 \mathrm{~h}$ prior to WCE and Klean Prep as used for colonoscopy was the most successful regimen and this would be our recommendation.

Since its introduction WCE has provided clinically useful information in the management of a wide variety of wellknown different bowel disorders, as shown in table $5^{3-6} 1012161822$ which shows that it is used most commonly for differing indications at different ages.

For example, in adult practice the third commonest indication is for coeliac disease despite the sensitivity of WCE being far from $100 \%$ for more subtle grades of villous atrophy. ${ }^{29}$ In childhood there are many different causes of enteropathy often with patchy mild changes for which the sensitivity of WCE is low. Consequently, malabsorption as an indication for WCE should be the last resort.

Table 5 Indication for wireless capsule endoscopy in different age groups

\begin{tabular}{|c|c|c|c|c|c|}
\hline \multicolumn{2}{|l|}{ Adults } & \multicolumn{2}{|l|}{ Children, 10-18 years } & \multicolumn{2}{|l|}{ Children, 1-8 years } \\
\hline Indication & $\%$ & Indication & $\%$ & Indication & $\%$ \\
\hline Obscure gastrointestinal bleeding & 48 & Suspected Crohn's disease & 45 & $\begin{array}{l}\text { Obscure gastrointestinal } \\
\text { bleeding }\end{array}$ & 37 \\
\hline Suspected Crohn's disease & 25 & $\begin{array}{l}\text { Obscure gastrointestinal } \\
\text { bleeding }\end{array}$ & 23 & Suspected Crohn's disease & 24 \\
\hline Coeliac disease & 20 & Polyposis & 22 & Abdominal pain & 14 \\
\hline Polyposis & 2 & Protein loss & 3 & Malabsorption & 14 \\
\hline \multirow[t]{2}{*}{ Protein loss } & 2 & Malabsorption & 3 & Protein loss & 10 \\
\hline & & Abdominal pain & 2 & Polyposis & 3 \\
\hline
\end{tabular}

Information concerning adults is taken from Mazzarolo and Brady, ${ }_{1}^{3}$ Gay and Delvaux ${ }_{1}^{4}$ Waterman and Eliakim ${ }^{5}$ and Delvaux and Gay. Information regarding children of 10-18 years is taken from Sant'Anna et al, ${ }^{10}$ Antao et al, ${ }^{12}$ Arguilles-Arias et al, ${ }^{16} \mathrm{Thomson}$ et $a l^{18}$ and Moy and Levine. 22

Information regarding children of 1-8 years is from the present study. 
More recently, new roles have been suggested including the diagnosis of small intestinal neoplasms, ${ }^{31}$ the evolution of inflammatory bowel disease ${ }^{21}$ and in graft versus host disease. ${ }^{32}$

To date the few studies that have been carried out in children $>10$ years show that WCE has particularly a role in the diagnosis of small intestinal Crohn's disease, obscure GI bleeding, and polyposis syndromes. ${ }^{210121416-26}$ Our data in younger children suggest that obscure GI bleeding is the commonest indication as in adults (see table 4), being $35 \%$ of those studied. This is at variance with older children, in whom it accounted for only 13-24\% ${ }^{10} 12161822$ overall. Another marked difference is represented by the underlying aetiology of the haemorrhage. In our study $6 / 16$ of the bleeding lesions were associated with congenital and genetically determined disorders including Meckel's diverticulae, reduplication cysts, and PeutzJegher syndrome, whilst in older children and adults this was not the case.

Suspicion of Crohn's disease was the second most frequent indication, accounting for $24 \%$ in our study. In three of these cases evidence of additional Crohn's disease in the colon was found on WCE despite previous negative colonoscopy, which makes falsely negative endoscopy an important cause of undetected disease. In contrast, in studies of older children, Crohn's disease accounted for 40-66\%. ${ }^{10} 12161822$ The difference in indication is due to the age of peak presentation. ${ }^{38}$ Overall, the indications for WCE in this study of small children were similar to older children and adults, but they were differently distributed. The underlying diseases especially those causing GI bleeding were also different and congenital or genetically determined conditions were frequently present.

Furthermore, in the case of bleeding, protein loss, and malabsorption with no other abnormal findings it is clear that WCE might be helpful. However, our data also shows that $25 \%$ of those who were investigated for recurrent abdominal pain were suffering from Crohn's disease. As at least one study has shown that WCE has a higher sensitivity for small bowel pathology than either radiology or endoscopy ${ }^{18}$ then we would suggest that WCE should be carried out after upper GI endoscopy has excluded oesophageal and gastric pathology.

Our study demonstrates that WCE is just as useful and equally as safe in small children as in older children or adults. Much younger children than expected were able to swallow the device when challenged in a child-acceptable fashion. In the very small children endoscopic introduction was necessary which proved safe and reliable if an adequate device was used. Our study, performed in nine centres across Europe, showed that, although in individual centres there were differences in handling, the above statements are valid in a wide variety of health settings.

Acknowledgements: We gratefully acknowledge the preliminary post-mortem studies carried out by Professor R Penning, Institut fur Rechtsmedezin, LudwigMaximilian University, Munich, Germany. We thank Professor S Koletzko, LudwigMaximilian University, Dr K-L Kolho, Children's Hospital, Helsinki, Finland, and Dr L Dall'Oglio, Bambino Gesu Hospital, Rome, Italy, for helpful discussions, the recruitment of patients and comments on the manuscript. We are grateful for the technical support provided by Given Imaging, Hamburg, Germany.

Competing interests: None.

Ethics approval: Approval was obtained from the appropriate Ethics Review Board for each of the participating centres.

Provenance and peer review: Not commissioned; externally peer reviewed

\section{REFERENCES}

1. Marmo R, Rotondano G, Piscopo R, et al. Meta-analysis: capsule enteroscopy vs conventional modalities in diagnosis of small bowel diseases. Aliment Pharmacol Ther 2005;22:595-604.
2. Sidhu R, Sanders D, McAlindon M, et al. Capsule endoscopy and enteroscopy: modern modalities to investigate small bowel pathology in paediatrics. Arch Dis Child 2007; 93:154-9.

3. Mazzarolo S, Brady P. Small bowel capsule endoscopy: a systematic review. South Med J 2007;3:274-80.

4. Gay G, Delvaux M. Small-bowel endoscopy. Endoscopy 2008;40:140-6.

5. Waterman M, Eliakim R. Capsule enteroscopy of the small intestine. Abdom Imaging Published Online First 25 June 2008. doi: 10.1007/s00261-008-94315.

6. Delvaux M, Gay G. Capsule endoscopy: technique and indications. Best Pract Res Clin Gastroenterol 2008;22:813-37.

7. Li F, Gurudu SR, De Petris G, et al. Retention of the capsule endoscope: a singlecenter experience of 1000 capsule endoscopy procedures. Gastrointest Endosc 2008;68:174-80.

8. Nathan SR, Biernat L. Aspiration - an important complication of small-bowel video capsule endoscopy. Endoscopy 2007;39(Suppl 1):E343.

9. Rondonotti E, Villa F, Mulder CJ, et al. Small bowel capsule endoscopy in 2007: indications, risks and limitations. World J Gastroenterol 2007;13:140-9.

10. Sant'Anna AM, Dubois J, Miron M-C, et al. Wireless capsule endoscopy for obscure small-bowel disorders: final results of the first pediatric controlled trial. Clin Gastroenterol Hepatol 2005;3:264-70.

11. El Matary W. Wireless capsule endoscopy: Indications, limitations and future challenges. J Pediatr Gastroenterol Nutr 2008;46:4-12.

12. Antao B, Bishop J, Shawis R, et al. Clinical application and diagnostic yield of wireless capsule endoscopy in children. J Lap Adv Surg Tech 2007;3:364-9.

13. Fritscher-Ravens A, Swain CP. The wireless capsule: new light in the darkness. Dig Dis 2002;20:127-33.

14. Silbermintz A, Levine J. Capsule endoscopy in the evaluation of patients with suspected Crohn's disease: expanding experience into the pediatric age group. IMAJ 2008; 10:468-72.

15. Chami G, Raza M, Bernstein CN. Usefulness and impact on management of positive and negative capsule endoscopy. Can J Gastroenterol 2007;21:577-81.

16. Arguilles-Arias F, Caunedo A, Romero J, et al. The value of capsule endoscopy in pediatric patients with a suspicion of Crohn's disease. Endoscopy 2004;36:869-73.

17. de'Angelis GL, Fornaroli F, de'Angelis N, et al. Wireless capsule endoscopy for pediatric small-bowel diseases. Am J Gastroenterol 2007;102:1749-57.

18. Thomson M, Fritscher-Ravens A, Mylonaki M, et al. Wireless capsule endoscopy in children: a study to assess diagnostic yield in small bowel disease in paediatric patients. J Pediatr Gastroenterol Nutr 2007;44:192-7.

19. Shamir R, Hino B, Hartman C, et al. Wireless video capsule in pediatric patients with functional abdominal pain. J Pediatr Gastroenterol Nutr 2007;44:45-50.

20. Mezoff A, Prued'Homme D, Hodges C, et al. Capsule endoscopy in pediatric patients with hamartomatous polyp syndromes. J Pediatr Gastroenterol Nutr 2006;42:240-2.

21. Cohen SA, Gralnek IM, Ephrath $\mathrm{H}$, et al. Capsule endoscopy may reclassify pediatric inflammatory bowel disease: a historical analysis. J Pediatr Gastroenterol Nutr 2008;47:31-6.

22. Moy L, Levine J. Wireless capsule endoscopy in the pediatric age group: experience and complications. J Pediatr Gastroenterol Nutr 2007;44:516-20.

23. Ge Z-Z, Chen H-Y, Gao Y-J, et al. Clinical application of wireless capsule endoscopy in pediatric patients for suspected small bowel diseases. Eur J Pediatr 2007;166:825-9.

24. Kavin H, Berman J, Martin TL, et al. Successful wireless capsule endoscopy for a 2.5-year-old child: obscure gastrointestinal bleeding from mixed, juvenile, capillary hemangioma-angiomatosis of the jejunum. Pediatrics 2006;117:539-43.

25. Aabaken L, Scholz T, Ostensen AB, et al. Capsule endoscopy is feasible in small children. Endoscopy 2003;35:798.

26. Tabbers MM, Bruin KF, Benninga MA, et al. Capsule endoscopy in a child with a jejunal hemangioma. Endoscopy 2006;38(Suppl 2): E46.

27. Christodoulou DK, Haber G, Beejay U, et al. Reproducibility of wireless capsule endoscopy in the investigation of chronic obscure gastrointestinal bleeding. Can J Gastroenterol 2007;21:707-14.

28. Fritscher-Ravens A, Swain P, von Herbay A. Refractory Whipple's disease with anaemia: first lessons from capsule endoscopy. Endoscopy 2004;36:659-62.

29. Ersoy 0, Akin E, Ugras S, et al. Capsule endoscopy findings in celiac disease. Dig Dis Sci 2009;54:825-9.

30. De Palma GD, Rega M, Ciamarra P, et al. Small-bowel polyps in Peutz-Jeghers syndrome: diagnosis by wireless capsule endoscopy. Endoscopy 2004;36:1039.

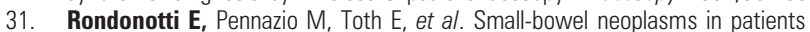
undergoing video capsule endoscopy: a multicenter European study. Endoscopy 2008;40:488-95.

32. Meister T, Heinzow H, Bisping G, et al. Intestinal graft-versus-host-disease staging by video capsule endoscopy. Endoscopy 2008;40(Suppl 2): E144.

33. Barth BA, Donovan K, Fox V. Endoscopic placement of the capsule endoscope in children. Gastrointest Endosc 2004;60:818-21.

34. Fritscher-Ravens A, Mills T, Mosse A, et al. A study of devices for insertion and retrieval of wireless capsule endoscopes. Endoscopy 2002;XX(Suppl 34):A90.

35. Di Lorenzo C, Rasquin A, Forbes D, et al. Childhood functional gastrointestinal disorders: child/adolescent. Gastoenterology 2006;137:1527-37.

36. Williams CB, Laage NJ, Campbell CA, et al. Total colonoscopy in children. Arch Dis Child 1982;57:49-53.

37. Seidman EG, Costea F, Dirks MH. Performing capsule endoscopy in pediatric patients. Tech Gastrointest Endosc 2006;8:149-53.

38. Logan RFA. Inflammatory bowel disease incidence: up, down or unchanged? Gut 1998;42:309-1. 


\section{GUT}

\section{The feasibility of wireless capsule endoscopy in detecting small intestinal pathology in children under the age of 8 years: a multicentre European study}

A Fritscher-Ravens, P Scherbakov, P Bufler, et al.

Gut 2009 58: 1467-1472 originally published online July 21, 2009

doi: 10.1136/gut.2009.177774

Updated information and services can be found at:

http://gut.bmj.com/content/58/11/1467.full.html

\section{These include:}

References This article cites 36 articles, 2 of which can be accessed free at: http://gut.bmj.com/content/58/11/1467.full.html\#ref-list-1

Article cited in:

http://gut.bmj.com/content/58/11/1467.full.html\#related-urls

Email alerting Receive free email alerts when new articles cite this article. Sign up in service the box at the top right corner of the online article.

Topic Articles on similar topics can be found in the following collections Collections

Notes

To request permissions go to:

http://group.bmj.com/group/rights-licensing/permissions

To order reprints go to:

http://journals.bmj.com/cgi/reprintform

To subscribe to BMJ go to:

http://group.bmj.com/subscribe/ 